\title{
Impacto de las candidaturas independientes frente a los partidos políticos en México (2015-2020)
}

Impact of independent candidates against political parties in Mexico

(2015-2020)

IvONNE MAYA EsPINOZA

$0^{\circ}$ IUS Comitiãlis / Año 4, Número 7 / enero - junio 2021 / pp. 7-34 / ISSN: 2594-1356 Recepción: 6 de abril de 2020 / Aceptación: 5 de octubre de 2020

\section{(C) $(1)(0)$}

Esta obra está bajo licencia Creative Commons

Attribution-NonCommercial-ShareAlike 4.0

International (CC BY-NC-SA 4.0)

Resumen: El presente trabajo pretende determinar el grado de impacto de las Candidaturas Independientes (CIs) en las elecciones gubernamentales en México, celebradas de 2015 a 2020, frente a los partidos políticos. Con dicho fin se analizaron datos empíricos de las elecciones locales celebradas en los 31 Estados de la República mexicana para elegir Gobernador (33 ordinarias y dos extraordinarias). Del análisis de los datos se determinó que el impacto de las Candidaturas Independientes fue bajo (sólo un Estado es Gobernado por un CI), comparado con el alto impacto que tuvieron los partidos políticos en las elecciones gubernamentales al obtener las gobernaturas en casi todos los Estados.

Palabras clave: Candidaturas, Independientes, Partidos, Políticos, México.

Abstract: The present work tries to determine the degree of impact of the Independent Candidacies (CIs) in the government elections in Mexico, held from 2015 to 2020, in front of the political parties. To this end, empirical data from local elections held in the 31 states of the Mexican Republic to elect Governor (33 ordinary and two extraordinary) were analyzed. From the analysis of the data, it was determined that the impact of the Independent Candidacies was low (only one State is Governed by an IC), compared to the high impact that political parties had on government elections when obtaining governorships in almost all States.

Key words: Candidacies, Independents, Parties, Politicians, Mexico.

https://orcid.org/0000-0001-9220-4737.

Correo electrónico: maya@mixteco.utm.mx e ivonne7776@gmail.com

${ }^{1}$ Universidad Tecnológica de la Mixteca (UTM), Instituto de Ciencias Sociales y Humanidades (ICSyH), Huajuapan de León, Oaxaca, México. Candidata al Sistema Nacional de Investigadores e integrante de la Red de Politólogas \#No Sin Mujeres. 


\section{INTRODUCCIÓN}

Durante siete décadas México estuvo inmerso en un sistema de partido hegemónico, el cual finalizó con la alternancia en los poderes Legislativo y Ejecutivo en 1998 y 2000 respectivamente. Sin embargo, la crisis en el sistema de partidos persiste; así lo demuestran los resultados de encuestas sobre el desencanto ciudadano (Latinobarómetro, 2016) que evidencian la desconfianza de los ciudadanos hacia los partidos políticos, de acuerdo con datos del Observatorio de Elites Parlamentarias en América Latina (PELA, 2016). Dicho desencanto ha originado cambios en el sistema de partidos, tal es el caso de la reintroducción de los Candidatos Independientes (CIs) como una alternativa para hacer frente a la crisis partidista.

A nivel federal, la regulación de las CIs se ha dado paulatinamente a través de tres reformas a la Constitución Política de los Estados Unidos Mexicanos (CPEUM): a) la primera en 2012, reintrodujo la figura del CI, ya que desde 1946 para ser candidato a un puesto de elección popular era necesario ser propuesto por un partido político (CPEUM, 2015, p. 41); b) la segunda en 2013, incorporó el principio de que las constituciones y leyes locales garanticen que en las elecciones los ciudadanos soliciten su registro como CIs a todos los cargos de elección popular; y c) la tercera en 2014, otorgó a los CIs derechos y obligaciones en las mismas condiciones que a los candidatos de partido, dichas prerrogativas incluían el acceso a postulación, registro, radio y televisión; financiamiento público, franquicias postales, nombramiento de representantes ante las mesas directivas de casilla (MDC), así como la obligación de presentar su contabilidad y plan de reciclaje de propaganda (CPEUM, 2015).

A nivel local, las constituciones y leyes de los estados han regulado el acceso a las CIs a través de adecuaciones realizadas entre 2014 y 2015. Cada Estado ha decidido el porcentaje y los plazos para recabar el apoyo ciudadano, así como los requisitos para el registro de los CIs, de ahí que existan diferencias sustanciales entre los diferentes Estados de la República Mexicana.

El presente artículo tiene como objetivo comparar el impacto de las CIs frente a los partidos políticos en las elecciones locales celebradas durante el periodo de 2015 a 2020 estas con el fin de elegir Gobernador en cada uno de los Estados que integran la República Mexicana, con ello determinar si las CIs han ayudado a disminuir la crisis del sistema de partidos en México y lograr su fortalecimiento.

La hipótesis a comprobar supone que el impacto de las CIs ha sido bajo, frente al impacto de los partidos políticos en las elecciones locales celebradas en los Estados de la República Mexicana, por lo que las CIs no han disminuido la crisis del sistema de partidos en México ni han logrado su fortalecimiento. La hipótesis parte de que las CIs fueron reintroducidas en el sistema de partidos mexicanos para hacer frente a la crisis de credibilidad que actualmente presenta, sin embargo, su impacto en las elecciones 
locales ha sido bajo y no ha logrado fortalecer el sistema de partidos.

Para cumplir con el objetivo se recabaron y analizaron datos empíricos de 35 elecciones locales para elegir Gobernador (23 ordinarias y dos extraordinarias), celebradas en 31 Estados de la República Mexicana entre 2015 y 2020, con los resultados obtenidos se elaboraron cuatro tablas y una figura. La primera tabla da cuenta de dos aspectos; el primer porcentaje de apoyo ciudadano requerido por Estado para ser registrado CI y el plazo para la obtención del apoyo; la Tabla 2 señala las causas que originaron que los Aspirantes a Candidatos Independientes (ACIs) no obtuvieran su registro como CIs; la Tabla 3, da cuenta del número de ACIs que participaron en los procesos electorales, y del número de CIs registrados (ACIs que lograron reunir todos los requisitos); la Tabla 4 señala qué partido político o CI ganó la elección en cada uno de los Estados; finalmente la figura da cuenta de la confianza que los ciudadanos mexicanos tienen en los partidos políticos.

El artículo está dividido en siete partes: la primera, relativa al marco teórico-conceptual que señala los conceptos y teorías que sirven de base a la investigación y establece los antecedentes de las CIs en México; la segunda expone la desconfianza de los ciudadanos en el sistema de partidos; la tercera, da cuenta de los porcentajes y plazos para solicitar el apoyo ciudadano en cada uno de los 31 Estados que celebraron elecciones en 2015 y 2020; la cuarta, analiza las causas por las cuales los ACIs no obtuvieron su registro; la quinta, expone la participación de los ACIs y los CIs en las 35 elecciones locales celebradas en la República Mexicana para elegir Gobernador; y la sexta, determina el impacto de las CIs en el sistema de partidos. Finalmente, se exponen las conclusiones generales.

\section{MARCO TEÓRICO-CONCEPTUAL}

En México el sistema de partido que precedió a la democracia fue el de partido hegemónico, entendiendo por sistema de partidos o como "el sistema de las interacciones que resultan de la competición entre los partidos” (Sartori, 2005, p. 13). En los sistemas de partido hegemónico este "[...] no permite una competencia oficial por el poder, ni una competencia de facto" (Sartori, 2005, p. 282). En este sistema "se permite que existan otros partidos, pero como partidos de segunda” (Sartori, 2005, p. 282); si bien están autorizados, no compiten con el partido hegemónico en términos antagónicos ni de igualdad. Dicho sistema no debe ser confundido con el de partido único ya que "esta distinción reviste una importancia notable, pues, entre otras cuestiones, los regímenes políticos de partido único han sido, en general, más represivos que los de partido hegemónico" (Lizcano y otros, 2013, p. 61).

El régimen de partido hegemónico ejercido, durante más de siete décadas, por el Partido Revolucionario Institucional (PRI) finalizó con la inserción del Partido Acción Nacional (PAN) a la presidencia de la República en el año 2000. Sin embargo, la alternancia en el poder no consiguió terminar con la crisis del sistema de partidos a la 
que hacen referencia diversos autores desde hace décadas (Boudon, 1998; Loaeza y Segovia, 1987 y Reyes, 1995).

La Reforma Constitucional de 2012 introdujo las CIs como una alternativa ciudadana ante la crisis de partidos, sin embargo, no garantizaba la equidad de la contienda entre los ciudadanos independientes y los candidatos propuestos por un partido político; por lo tanto, se hizo necesaria la Reforma de 2014 que modificó la normatividad para transformar las instituciones y las reglas de la competencia electoral. De acuerdo con Castellanos (2014) los objetivos de la Reforma son: "fortalecer la participación ciudadana en la política y ampliar la representación popular para enfrentar su crisis" (p.70), "garantizar la equidad de las elecciones en cuanto al acceso y uso de financiamiento” (p. 88), y "dar mayor certidumbre, transparencia y estabilidad al sistema político" (p. 43).

Para González los candidatos son “aquellos a quienes les está permitido, según las disposiciones electorales, participar en las elecciones cubriendo simplemente los requisitos de elegibilidad en ella establecidos" (2010, p. 48). Por lo tanto, el elemento central para ser considerado candidato es el de la reunión de requisitos, así que, quién cumpla con lo señalado en la normatividad podrá ser registrado como candidato.

¿Cuál es la diferencia entre un candidato independiente y uno de partido? La CPEUM (2015) y la normatividad federal no definen las CIs; por su parte, la Ley General de Instituciones y Procedimientos Electorales (LEGIPE) solo menciona que CI es "el ciudadano que obtenga por parte de la autoridad electoral el acuerdo de registro, habiendo cumplido los requisitos que para tal efecto establece la presente Ley" (LEGIPE, 2014, art. 3, inciso c); por lo tanto, es necesario recurrir a la literatura para definir con mayor claridad a las CIs.

Zovatto define a las CIs como "la nominación para ocupar un cargo electivo, cuyo rasgo peculiar y sobresaliente consiste en que tal oferta política se realiza sin el concurso ni principal ni complementario de un partido político" (2008, p. 137). El Instituto Nacional de Estudios Políticos A.C. (INEP, 2002) señala que un CI "es un aspirante a un cargo de elección popular que no está afiliado a un partido político” (p. 17); así pues, de acuerdo con la normatividad y las definiciones señaladas, los CIs son aquellos ciudadanos que cumplen con los requisitos establecidos en la normatividad para registrarse ante un órgano electoral (ya sea local o federal) para contender por un cargo de elección popular, sin estar afiliados a un partido político.

La diferencia entre los CIs y los candidatos de partido radica en que estos últimos están afiliados a un partido político registrado, ya sea a nivel federal y/o local, que apoya su candidatura. Los candidatos de partido han estado presentes en la vida política del país desde que es independiente, a diferencia de los CIs que salieron de la escena política durante casi todo el periodo de partido hegemónico.

Las CIs han estado presentes en la vida política del país desde la época independiente; sin embargo, durante más de seis décadas desaparecieron de la escena política, tiempo que coincide con el establecimiento del régimen de partido hegemónico. 
De acuerdo con Hernández (2012, pp. 20-26) las CIs en México han pasado por tres periodos: El primero, de los ciudadanos candidatos (1824-1911), este periodo se caracterizó porque no se hacía referencia a los CIs, mucho menos había una reglamentación; sin embargo, era común la participación de CIs en las elecciones. El segundo, del reconocimiento institucional de los CIs (1911-1946), en este periodo se reconocieron legalmente las CIs (con dicha denominación) y se establecieron disposiciones mínimas para su funcionamiento. El tercero, del rechazo a las CIs (1946-2012), durante este periodo solo a través de los partidos políticos era posible acceder a una candidatura.

Después de las reformas constitucionales del 2012, 2013 y 2014, a estos tres periodos hay que sumar uno más que corresponde a la sistematización de las CIs del 2012 a la fecha, este periodo se caracteriza por la reintroducción de las CIs en un régimen distinto: el democrático.

El escenario político electoral de este cuarto periodo difiere del segundo, ya que si bien en ambos existe un reconocimiento institucional de las CIs el contexto es distinto. Las diferencias principales son dos: a) En el segundo periodo se establecieron disposiciones "mínimas" para el funcionamiento de las CIs; actualmente las reformas constitucionales a nivel federal y local han "sistematizado" a través de la reglamentación el funcionamiento de las CIs a nivel federal y local, si bien hace falta trabajar en las condiciones de equidad e igualdad entre los CIs y los candidatos de partido, las CIs constituyen un avance significativo para que los ciudadanos accedan al poder. b) La institucionalización de las CIs durante el segundo periodo se llevó a cabo en un régimen semi- democrático, y la reintroducción de las CIs en el cuarto periodo se realizó en un régimen democrático de reciente adquisición.

El régimen democrático abre el "acceso legal” al poder a los ciudadanos; sin embargo, es necesario hacer ajustes para que estos "accedan realmente" al poder en igualdad de condiciones que los candidatos de partido.

\section{DESCONFIANZA EN EL SISTEMA DE PARTIDOS}

En varios países de América Latina la confianza en las instituciones ha ido disminuyendo, particularmente la depositada en los partidos políticos; México no es la excepción. En las encuestas anuales realizadas por el Latinobarómetro (2016), desde 1995 hasta 2015 (excepto en 1999, 2012 y 2014) se evidencia la desconfianza que los ciudadanos mexicanos tienen en los partidos políticos. Las encuestas preguntaron a más de mil ciudadanos (en todo el país, en zonas rurales y urbanas) ¿Cuánta confianza tiene usted en los partidos políticos?, las opciones de respuesta eran cuatro: mucha, algo, poca o ninguna; las respuesta "ninguna" y "poca" son las que obtuvieron un mayor porcentaje en todo el periodo, "algo" se ubicó en un término medio y "mucha” fue la que obtuvo menor porcentaje (Figura 1).

La respuesta "ninguna" tuvo su menor porcentaje en 1995, 1997 y 1998 con el 
$22 \%$ y en 2003 obtuvo el porcentaje más alto $60 \%$. En cuanto a "poca" confianza ha oscilado entre $29 \%$ en 2003 y el $50 \%$ en 2004 . Por su parte, "algo" de confianza se ha ubicado entre el 10\% en 2003 y el 35\% en 1995. En cuanto a "mucha" confianza su menor porcentaje fue en 2002 y 2003 con 1\%, el mayor en 2006 con 6\%. El mayor descenso de la confianza ciudadana se observa en 2003, donde "ninguna" confianza obtuvo el 60\%, seguido de "poca" confianza en 2004 con el 50\%. Así los mexicanos encuestados han manifestado tener "ninguna" o "poca" confianza en los partidos políticos.

Figura 1: Confianza en los partidos políticos mexicanos (1995-2015).

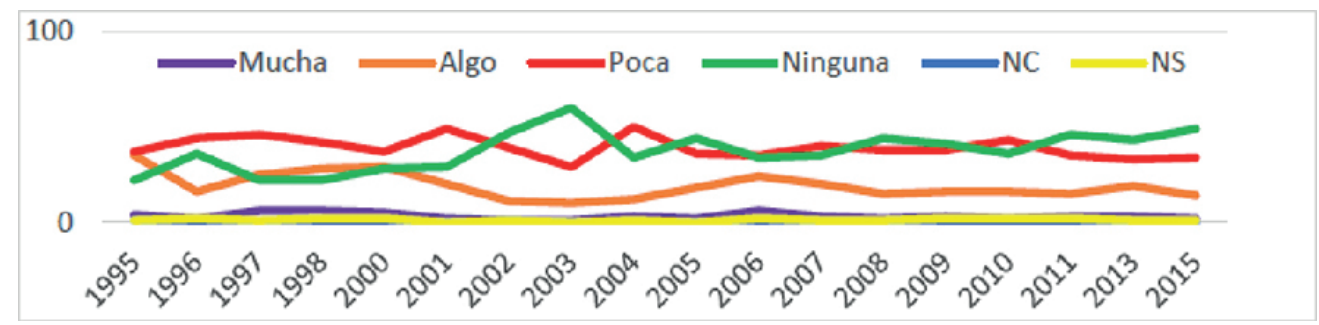

Fuente: elaboración propia con datos de Latinobarómetro (2016). Notas: NC= no contesto y NS: no sabe

La desconfianza de los ciudadanos hacia los partidos políticos está generando cambios en el sistema de partidos como: la introducción de los CIs o la creación de partidos emergentes como Movimiento Ciudadano (MC) o Morena (Movimiento de Regeneración Nacional) que lograron obtener un importante número de escaños en la elección de Diputados Federales 2015. Dicha elección modificó la conformación de la Cámara, de un tripartidismo: PRI-PAN-PRD (Partido de la Revolución Democrática) a un multipartidismo integrado, principalmente, por seis partidos: PRI (40,8\%), PAN (21,6\%), PRD (11\%), PVEM (9,4\%), Morena (7\%) y MC (5\%) (Maya, 2016a).

¿Qué generó la desconfianza?, son varios los factores.

Borja señala que, lamentablemente, por diversas circunstancias, en los últimos tiempos una ola de crisis y desprestigio ha envuelto a los partidos en todas partes del mundo. En algunos lugares ha sido la corrupción de sus dirigentes, en otros su caudillismo o su personalismo, en otros el clientelismo de su acción, o su incipiente institucionalización (2002, p. 768).

Palazuelos (2012) lo atribuye a la distorsión de la voluntad de los ciudadanos, precisamente por causa de la monopolización no solo del poder político sino también de la vida política organizada; en esta lógica pesa sobremanera la designación de candidatos bajo criterios que son ajenos a los intereses de los ciudadanos (p. 82).

Paramio (1999) argumenta que la desconfianza se generó por "la incapacidad de los gobiernos para resolver los nuevos desafíos traídos por la crisis estructural” (p. 191). En general, de acuerdo con Borja (2002), Palazuelos (2012) y Paramio (1999) los 
factores que ocasionan la desconfianza de los ciudadanos en los partidos políticos son múltiples: corrupción, caudillismo, clientelismo, falta de institucionalización, abuso del poder e incapacidad de resolver las demandas ciudadanas.

Estos factores se relacionan con el caso de México que en 2000 conoció la alternancia, al ganar la Presidencia de la República (por primera vez en siete décadas) un partido político distinto al PRI: el PAN, mismo que se mantuvo en el poder hasta 2012; sin embargo, el PAN no logró resolver las demandas ciudadanas y el PRI regresó al poder en 2012 (bajo un régimen distinto al de sus años de gloria). Aún con la alternancia, entre el PRI y el PAN, la desconfianza en los partidos políticos persiste porque ninguno de los dos partidos ha logrado acabar con la corrupción y resolver las necesidades ciudadanas.

¿Qué necesidades, de los ciudadanos mexicanos, han sido incapaces de resolver los partidos políticos que han detentado el poder en las últimas décadas? De las encuestas realizadas en México entre 1994 y 2009 a los diputados de la Cámara Federal (representantes de los intereses ciudadanos en cada uno de los 300 distritos electorales en que se divide el país) por el Observatorio de Élites.

Parlamentarias en América Latina (PELA, 2016) infiere que las necesidades de los ciudadanos (de mayor a menor grado de importancia) son seis: seguridad, acabar con el narcotráfico, empleo, terminar con la corrupción, impulso a la actividad productiva y/o comercial, y acceso a la salud universal de calidad (Maya, 2016b).

Estas necesidades se hacen evidentes en los resultados de las encuestas del PELA (2016); por ejemplo en el siguiente cuestionamiento: "A continuación, le voy a nombrar una serie de problemas comunes a muchos países ¿podría indicarme, para cada uno de ellos, qué grado de importancia: mucha, bastante, poca o ninguna tienen hoy en México?”, los problemas señalados eran 14. De las respuestas de los diputados se obtuvieron porcentajes altos en seis de los problemas, sin embargo, cuatro de los seis tenían resultados más alarmantes; por lo tanto, los clasifiqué en dos grupos: a) los primeros cuatro, como muy importantes, y b) los dos segundos, como importantes. Los muy importantes rebasaron el $75 \%$ del promedio de las respuestas de "mucha importancia" y son: en primer lugar, la inseguridad ciudadana y la delincuencia que obtuvo un promedio de 80,92\%; en segundo lugar, el narcotráfico con el 78,22\%; en tercer lugar, el desempleo con el 76,95\%; en cuarto lugar, la corrupción con el 75,62\%.

Los importantes rebasaron el 50\% del promedio de las respuestas de "mucha importancia" y son: el estancamiento de la actividad productiva y/o comercial con el $62,55 \%$ y la sanidad (seguridad social) que obtuvo el $54,10 \%$ en promedio, ocupando el quinto y sexto lugar en importancia respectivamente. Los gobiernos en turno (tanto priistas como panistas) prometieron hacer frente a los problemas que aquejan al país, sin embargo, ante la incapacidad de erradicarlos o disminuirlos, la desconfianza de la ciudadanía en los partidos políticos aumentó.

La alternancia no resolvió los problemas de la ciudadanía, la desconfianza en los partidos políticos continuo y se hizo necesaria una reforma política que le diera 
nuevas opciones a los ciudadanos, fue así como se reintrodujeron las CIs en 2012.

\section{CANDIDATURAS INDEPENDIENTES EN ELECCIONES LOCALES (2015-2020)}

La primera incursión de las CIs, en un régimen democrático, que contendieron por una gubernatura se llevó a cabo en las elecciones ordinarias del 7 de junio de 2015, en la cual nueve estados celebraron elecciones para elegir Gobernador: Baja California Sur, Campeche, Colima, Guerrero, Michoacán, Nuevo León, Querétaro, San Luis Potosí y Sonora; de estos solo en tres (que representan el 33.3\% del total de los estados que tuvieron elecciones ese año) se registraron aspirantes a candidatos independientes: Campeche, Nuevo León y San Luis Potosí (ver Tabla 1). En Campeche, se registró como ACI por la gubernatura, Luis Antonio $\mathrm{Che} \mathrm{Cu}$, dirigente del Frente Campesino Independiente "Emiliano Zapata" (FRECIEZ); en Nuevo León, Jaime Heliodoro Rodríguez Calderón "El Bronco"; y en San Luis Potosí, se registraron dos aspirantes, Enrique Suárez del Real Díaz de León y José Alfredo Loredo Zarate.

De estos cuatro aspirantes, solo dos (50\%) lograron ser registrados como CI (al cumplir con todos los requisitos establecidos por la ley): Luis Antonio Che $\mathrm{Cu}$, y Jaime Heliodoro Rodríguez Calderón "El Bronco", el otro 50\% de los aspirantes no lograron la candidatura debido a que no cumplieron con la totalidad de los requisitos que cada Instituto o Comisión estatal solicitaba.

En las seis entidades restantes, que representan el 66.6\% de los estados que celebraron elecciones, no se registraron aspirantes a CI. Cabe aclarar que una de las nueve elecciones para elegir Gobernador, celebradas en 2015, fue anulada por el Tribunal Electoral del Poder Judicial de la Federación (TEPJF): la elección de gobernador de Colima, debido a que existió un "empate técnico" entre el candidato del PRI-PVEM-NA (39.82\%) y el del PAN (39.65\%) además de que el candidato del PAN denunció que el Secretario de Desarrollo Social (Sedesol) promovió el apoyo de la administración pública local al candidato del PRI-PVEM-NA; hecho que fue probado y motivo la anulación de la elección.

Posteriormente, el 17 de enero de 2016, Colima celebró su elección extraordinaria a la gubernatura del Estado, resultando electo el candidato del PRI-PVEM-NA (con el 43.23\% de los votos) seguido por el candidato del PAN (con el 39.53\%); en ambas elecciones (la ordinaria y la extraordinaria) no se registraron aspirantes a CI para la elección de gobernador.

En las elecciones de 2015 fueron pocos los ciudadanos que aspiraron a una CI (4), y solo la mitad de ellos (2) lograron obtener la candidatura, sin embargo, el resultado alentador fue que el CI de Nuevo León logró obtener la gubernatura con el 48.8\% de los votos, dejando atrás a sus adversarios: la Alianza "por tu seguridad" PRI-PVEM-PANAL-PRD, obtuvo el 23.8\%; y el PAN 22.3\%. Por lo tanto, del 100\% de aspi- 
rantes, $50 \%$ obtuvieron la candidatura y uno de ellos, que representa el $25 \%$, obtuvo la gubernatura del Estado.

En 2016, se realizó la segunda participación de CI para la elección de gobernadores, en este año doce estados celebraron elecciones: Aguascalientes, Chihuahua, Durango, Hidalgo, Oaxaca, Puebla, Quintana Roo, Sinaloa, Tamaulipas, Tlaxcala, Veracruz, Zacatecas. En diez estados se presentaron aspirantes a CI (83,3\%), y solo en dos no hubo aspirantes (16,6\%): Hidalgo y Quintana Roo. Probablemente, uno de los factores que influyó en el aumento del registro de aspirantes fue el triunfo del CI de Nuevo León (ver Tabla 1).

En Aguascalientes, se registró como aspirante, Gabriel Arellano Espinoza; en Chihuahua, José Luis Barraza González "Chacho"; en Durango, Alejandro Campa Avitia; en Oaxaca, se registraron tres aspirantes: Juan Manuel García López (de Transformar Oaxaca 2016 A.C) representante del Consorcio de la Industria Japonesa en Norteamérica y forma parte del Patronato Pro Defensa y Conservación del Patrimonio Cultural y Natural de Oaxaca, un movimiento fundado por el artista plástico, Francisco Toledo; Zenén Ávila Elena (de Confederación Nacional Revolucionaria de los Pueblos Dinámicos de México A.C) originario de la comunidad indígena mixteca San Agustín de Atenango, y Matías Romero Solano (de Matías Romero Solano A.C.) pertenece a la comunidad indígena triqui de Santiago Juxtlahuaca y fungió como presidente de la Cámara Nacional de la Industria Maderera; en Puebla, se registraron siete: Ricardo Jiménez Hernández, Ricardo Villa Escalera, Marco Antonio Mazatle Rojas, Ana Teresa Aranda Orozco "La Doña”, Rubén Hernández Pérez, Leodegario Pozos Vergara "El Tigre de la Sierra” y Carolina López López; en Sinaloa, Francisco Cuauhtémoc Frías Castro; en Tamaulipas, José Francisco Chavira Martínez; en Tlaxcala, Jacob Hernández Corona; en Veracruz, Juan Bueno Torio; y en Zacatecas, se registraron dos aspirantes, Alma Rosa Ollervides González y Rogelio Soto Acuña.

De los 19 ACI, únicamente 10 lograron obtener la CI (52,6\%), los candidatos de: Aguascalientes, Chihuahua, Durango, Sinaloa, Tamaulipas, Tlaxcala, Veracruz y Zacatecas; de los siete de Puebla solo una logró obtener la CI: Ana Teresa Aranda Orozco “La Doña”. Los tres ACI de Oaxaca no lograron obtener su registro como CI. Por lo tanto, en cuanto al porcentaje de CI aprobados frente a ACI ambas elecciones (2015 y 2016) son similares; pero en el resultado final son distintas, ya que en la elección de 2016 ningún CI logro obtener una gubernatura a diferencia de 2015.

En 2017, se realizaron elecciones de gobernador en tres Estados: Coahuila, Nayarit y Estado de México. En los tres estados se presentaron ACI, 8 en total, de los cuales 6 lograron su registro como CI (ver Tabla 1).

En Coahuila, se registraron tres aspirantes: Germán Maltos Reyna (pero se le negó el registro por no presentar cuenta bancaría a nombre de una asociación civil, ya que presentó el número de cuenta como persona física), Javier Guerrero García y Luis Horacio Salinas (Lucho); en Nayarit tres: Víctor Manuel Chávez Vázquez, Antonio Ayón Banuelos e Hilario Ramírez Villanueva; y en el Estado de México dos: Teresa Castell de Oro Palacios e Isidro Pastor Medrano, a este último el Tribunal Electoral del 
Estado de México le revocó el registro por irregularidades en las firmas de apoyo ciudadano por lo que sólo quedo en la contienda la primera aspirantes mencionada.

En 2018, se llevaron acabo ocho elecciones en los siguientes Estados: Jalisco, Guanajuato, Puebla, Tabasco, Chiapas, Yucatán, Veracruz y Morelos. En Jalisco y Guanajuato no se registraron ACI, en los seis estados restantes los ACI fueron los siguientes.

En Puebla se registraron tres ACI: Enrique Cárdenas Sánchez, José Jorge Morales Alducín e Israel de Jesús Ramos González, pero ninguno logró el numero de firmas necesario para lograr su registro como CI.

En Tabasco se presentó un ACI que obtuvo su registro como CI: Jesús Alí de la Torre, lo anterior debido a que la Ley Electoral y de Partidos Políticos del Estado de Tabasco (LEPPET, 2014, art.281) establece que sólo se registrará una candidatura independiente para cada cargo de elección popular por el principio de mayoría relativa.

El registro será individual, por fórmula o planilla, según corresponda. De existir más de un aspirante, fórmula o planilla a un mismo cargo de elección popular, será registrado el que obtenga el mayor número de respaldos ciudadanos, en cantidad superior al porcentaje señalado para cada cargo.

En Chiapas se presentaron cuatro ACI: Jesús Alejo Orantes Ruíz, Lenin Ostilio Urbina Trujillo, Jorge Aramando Padilla Valvidia y Horacio Culebro Borrayas; de los cuales solo el primero obtuvo su registro como CI, Lenin no obtuvó su registró por pretender computar firmas falsas y los otros dos no alcanzarón el número de firmas de respaldo ciudadano.

En Yucatán se presentaron cuatro ACI: Sofía Castro Romero, Felipe Neri Espinoza Herrera, Margarita Torres Sansores y Edwuin Palomino Sulub, sin embargo, ninguno obtuvo su registro como CI debido a que la primera de los aspirantes logró el número de firmas con irregularidades y los tres restantes no obtuvieron las firmas solicitadas.

En Veracruz se presentaron dos ACI: Simón Soto Hernández y Marisol Hernández Gómez, pero ninguno obtuvo su registro como CI; el primero de los aspirantes no logró obtener el número de firmas necesarias y la segunda, fue arrestada por el presunto secuestro de un menor de edad una semana después de su registro como ACI.

En Morelos siete ciudadanos solicitaron su registro como ACI: Fidel Demédicis Hidalgo, Ariosto Genel García, Yolanda Gutiérrez Neri, Mario Rojas Alba, Luis Sergio Hernández Coronado, Edgar Francisco Flores Miranda y José Antonio Sandoval Tajonar, de ellos solo uno (el primero de los mencionados) logró su registro como CI.

En 2019, solo dos Estados tuvieron elecciones para gobernador: Baja California y Puebla, este último en elecciones extraordinarias. 
Baja California tuvo cuatro registros de ACI: Temoc Ávila Hernández, Sergio Arturo Fernández Herrera, Arturo Marín Corona y Felipe Daniel Ruanova Zarate, pero ninguno obtuvo su registro como $\mathrm{CI}$ al no reunir el número de firmas solicitadas por las autoridades electorales en apego a la legislación local.

En Puebla, se presentaron cinco ACI: Israel de Jesús Ramos González, Erick Martínez Salazar, Miguel Ángel Ocampo Hernández, Juan Alejandro Amorós Herrera y Raymundo López Ortiz; pero ninguno obtuvo su registro como CI al no reunir el número de firmas requeridas, el primero de los aspirantes declinó un día antes de que terminara el plazo para recabar el número de firmas solicitadas al no conseguir las cédulas solicitadas con el apoyo ciudadano.

En general, en las elecciones de gobernador realizadas de 2015 a 2020, se han registrado como ACI 61 ciudadanos, de los cuales 21 han logrado ser registrados como CI (34,42\%), y solo uno (1.6\%) logró ganar la gubernatura.

\section{CAUSAS DE “NO REGISTRO” DE LOS ACI}

Las causas por las cuales los ACI no obtuvieron su registro se deben al incumplimiento de tres de los principales requisitos que marca la ley en cada uno de los estados: cédulas de apoyo ciudadano insuficientes, la falta de entrega de las cédulas y la falta de entrega de la solicitud.

De acuerdo con la Tabla 2 fueron 40 los ACI que no obtuvieron su registro como CI (resultado de restar a los $61 \mathrm{ACI}$ registrados los $21 \mathrm{CI}$ aprobados). En el caso de San Luis Potosí sus aspirantes no cumplieron con el número de cédulas requerido para ser registrados como CI, tenían que recabar 36, 034 cédulas que representaban el $2 \%$ de los ciudadanos que integraban la Lista Nominal y no lograron reunirlas. En el caso de Suárez:

Tan solo presentó 675 respaldos ciudadanos, de los cuales, una vez aplicada la verificación correspondiente por la DERFE del Instituto Nacional Electoral, únicamente le validó 645 respaldos ciudadanos, debiendo ser 36, 034 respaldos ciudadanos, cantidad que representa el $2 \%$ del Listado Nominal del Estado con corte al 30 de septiembre del año 2014 (CEEPACSLP, 2015a).

\section{Tabla 1: Candidatos independientes registrados en elecciones para Gobernador (2015-2020)}

\begin{tabular}{|c|c|c|c|c|c|c|c|c|c|c|c|c|c|c|c|}
\hline $\mathbf{N}$ & 2015 & ACI & CI & $\mathbf{N}$ & 2016 & ACI & CI 1 & $\mathbf{N}$ & 2017 & ACI & $|\mathbf{C I}|$ & $\mathrm{N}$ & 2019 & ACI & CI \\
\hline 1 & Baja California Sur (1) & 0 & 0 & 1 & Aguascalientes (10) & 1 (d) & $1 \mid 1$ & 1 & Coahuila (22) & 3 & 2 & 1 & Baja California (33) & 4 & 0 \\
\hline 2 & Campeche (2) & 1 (a) & 1 & 2 & Chihuahua (11) & $1(\mathrm{e})$ & 112 & 2 & Nayarit (23) & 3 & 3 & 2 & $\begin{array}{c}\text { Puebla } \\
\text { (Extraordinaria) (34) }\end{array}$ & 5 & 0 \\
\hline 3 & Colima $\left(3^{*}\right)$ & 0 & 0 & 3 & Durango (12) & $1(\mathrm{f})$ & \begin{tabular}{l|l}
1 & 3 \\
\end{tabular} & 3 & Estado de México (24) & 2 & 1 & $\frac{A+1,}{\mathbf{N}}$ & $\begin{array}{l}9 \\
2020\end{array}$ & \begin{tabular}{|l}
$\mathrm{CI}$ \\
$\mathrm{AC}$ \\
\end{tabular} & CI \\
\hline 4 & Guerrero (4) & 0 & 0 & 4 & Hidalgo (13) & 0 & $0 \frac{A C}{N}$ & $\begin{array}{l}\mathrm{ACI} \\
\mathbf{N}\end{array}$ & $\begin{array}{c}8 \\
2018\end{array}$ & $\begin{array}{l}\mathrm{CI} \\
\mathrm{ACI}\end{array}$ & & 0 & 0 & 0 & 0 \\
\hline
\end{tabular}




\begin{tabular}{|c|c|c|c|c|c|c|c|c|c|c|c|}
\hline $\mathbf{N}$ & 2015 & ACI & CI & $\mathbf{N}$ & 2016 & ACI & CI & $\mathbf{N}$ & 2018 & ACI & CI \\
\hline 5 & Michoacán (5) & 0 & 0 & 5 & Oaxaca (14) & $3(\mathrm{~g})$ & 0 & 1 & Jalisco (25) & 0 & 0 \\
\hline 6 & Nuevo León (6) & 1 (b) & 1 & 6 & Puebla (15) & $7(\mathrm{~h})$ & (i) & 2 & Guanajuato (26) & 0 & 0 \\
\hline 7 & Querétaro (7) & 0 & 0 & 7 & Quintana Roo (16) & 0 & 0 & 3 & Puebla (27) & 3 & 0 \\
\hline 8 & San Luis Potosí (8) & 2 (c) & 0 & 8 & Sinaloa (17) & $1(j)$ & 1 & 4 & Tabasco (28) & 1 & 1 \\
\hline \multirow[t]{7}{*}{9} & Sonora (9) & 0 & 0 & 9 & Tamaulipas (18) & $1(\mathrm{k})$ & 1 & 5 & Chiapas (29) & 4 & 1 \\
\hline & & & & 10 & Tlaxcala (19) & $1(\mathrm{l})$ & 1 & 6 & Yucatán (30) & 4 & 0 \\
\hline & & & & 11 & Veracruz (20) & $1(\mathrm{~m})$ & 1 & 7 & Veracruz (31) & 2 & 0 \\
\hline & & & & 12 & Zacatecas (21) & $2(\mathrm{n})$ & 2 & 8 & Morelos (32) & 7 & 1 \\
\hline & & & & 13 & Colima $\left(3^{* *}\right)$ & 0 & 0 & ACI & 21 & $\mathrm{CI}$ & 3 \\
\hline & Total & 4 & 2 & & Total & 19 & 10 & & & & \\
\hline & Total & & & & ACI & 61 & & CI| & 21 & & \\
\hline
\end{tabular}

Notas: $\mathrm{ACI}=$ Aspirantes a Candidatos Independientes; $\mathrm{CI}=$ Candidatos Independientes; (a) Luis Antonio Che $\mathrm{Cu}$, dirigente del Frente Campesino Independiente "Emiliano Zapata" (FRECIEZ); (b) Jaime Heliodoro Rodríguez Calderón "El Bronco”; (c) Enrique Suarez del Real Díaz de León y José Alfredo Loredo Zarate; (d) Gabriel Arellano Espinoza; (e) José Luis Barraza González "Chacho"; (f) Alejandro Campa Avitia; (g) Juan Manuel García López, de Transformar Oaxaca 2016 A.C; Zenén Ávila Elena, de Confederación Nacional Revolucionaria de los Pueblos Dinámicos de México A.C; y Matías Romero Solano, de Matías Romero Solano A.C.; (h) Ricardo Jiménez Hernández, Ricardo Villa Escalera, Marco Antonio Mazatle Rojas, Ana Teresa Aranda Orozco “La Doña”, Rubén Hernández Pérez, Leodegario Pozos Vergara "El Tigre de la Sierra” y Carolina López López; (i) Ana Teresa Aranda Orozco “La Doña”; (j) Francisco Cuauhtémoc Frías Castro; (k) José Francisco Chavira Martínez; (l) Jacob Hernández Corona; (m) Juan Bueno Torio; (n) Alma Rosa Ollervides González y Rogelio Soto Acuña. Fuentes: elaboración propia con datos de (1) IEEBCS, 2016; (2) IEEC, 2016; (3*) IEECO, 2016 y (3*) Elección extraordinaria; (4) IEPCEG, 2016; (5) IEM, 2016; (6) CEENL,2016; (7) IEEQ, 2016; (8) CEEPACSLP, 2016; (9) IEEPACS, 2016; (10) IEEA, 2016; (11) IEECH, 2016; (12) IEPCD, 2016; (13) IEEH, 2016; (14) IEEPCO, 2016a; (15) IEEP, 2016; (16) IEQR, 2016; (17) IEES, 2016; (18) IETAM, 2016; (19) IETLAX, 2016; (20) IEV , 2016; (21) IEEZ, 2016;(22) IEEC, 2020; (23) IEEN, 2020; (24) IEEM, 2020; (25) IEPCJ, 2020; (26) IEEG, 2020; (27) IEEP, 2020; (28) IEPCT, 2020; (29) IEPCCH, 2020; (30) IEPCY, 2020; (31) IEV, 2020; (32) IMPEPAC, 2020; (33) IEEBC, 2020; y (34) IEEP, 2020.

Por lo que respecta a Loredo, presentó su desistimiento después de la dificultad para recabar el respaldo ciudadano, ya que de las 675 cédulas presentadas solo 3 fueron aprobadas (CEEPACSLP, 2015b).

En cuanto a los tres ACI de Oaxaca, no obtuvieron su registro como CI debido a que no reunieron el número de manifestaciones de apoyo requeridas en el plazo establecido. En este Estado "la Lista Nominal de Electores con corte al 31 de agosto de 2015 tenía: 2, 670, 881 ciudadanos registrados, el 2\% equivalía a: 53, 418 ciudadanos" (IEEPCO, 2016a , párr. 2), y los ACI debían recabar dichas manifestaciones en un mínimo de 13 de los 25 distritos con que cuenta el Estado. En el caso de García, reunió 2,556 (dos mil quinientas cincuenta y seis) cédulas de apoyo ciudadano, de las cuales 1,276 (mil doscientas setenta y seis) cédulas eran originales y 1, 280 (mil doscientas ochenta) eran fotocopias de cédulas de apoyo ciudadano. Al contabilizar sólo las cedulas originales se sumó un total de 11, 802 (once mil ochocientos dos) apoyos ciudadanos que representan el $0.4 \%$ de la Lista Nominal, y en ningún distrito obtuvo más del $1 \%$ de la Lista Nominal. Cabe aclarar que de acuerdo con el IEEPCO aun cuando se hubieran contabilizado todas las cédulas habría reunido 26, 600 (veintiséis mil seiscientos) apoyos, los cuales resultaban insuficientes para proceder al registro (IEEPCO, 2016b); Sánchez señala que "tras la revisión que realizó el Instituto Nacional Electoral (INE) se concluyó que mil 496 credenciales no fueron localizadas en el Regis- 
tro Federal de Electores; 102 correspondían a ciudadanos de otros estados, 521 estaban dadas de baja del Padrón Electoral, y 447 estaban duplicadas” (2016, párr. 4).

Situación similar ocurrió con Ávila que reunió 3, 887 (Tres mil ochocientos ochenta y siete) firmas, las cuales resultaron insuficientes para realizar el registro, por lo tanto "El INE reportó que 387 no fueron localizadas en el Registro Federal de Electores, 53 estaban dadas de baja, 19 eran de ciudadanos de otros estados, 94 estaban duplicadas. Además, la autoridad electoral detectó que ambos candidatos compartieron 13 firmas de apoyo y credenciales de elector de los mismos ciudadanos” (Sánchez, 2016, párr. 5).

Romero, de acuerdo con Noticias, Voz e Imagen (NVI) "no entregó el formato de apoyo ciudadano requerido por el Instituto Estatal Electoral y de Participación Ciudadana de Oaxaca (IEEPCO) en el plazo establecido" (2016, párr. 1). Del expediente de García, que fue el ACI que más cerca estuvo de obtener el registro de CI, el IEEPCO emitió un acuerdo: IEEPCO-CG-36/2016 (IEEPCO, 2016b), de los expedientes de Ávila y Romero no se emitieron acuerdos, por lo tanto, los datos que se obtuvieron provienen del informe que emitió la Dirección de Partidos Políticos del Instituto Estatal Electoral y de Participación Ciudadana (IEEPCO) ante los medios de comunicación como el diario El Norte y NVI.

Por lo que respecta a los seis ACI de Puebla que no obtuvieron su registro como CI esto se debió a dos motivos: a) no entregaron su solicitud de registro, y b) no reunieron el número de manifestaciones de apoyo solicitado. En el primer caso, se ubican cinco ACI: Ricardo Luis Alfonso Villa Escalera, Marco Antonio Mazatle Rojas, Rubén Hernández Pérez, Leodegario Pozos Vergara "El Tigre de la Sierra” y Carolina López López. En el segundo caso se ubica Ricardo Jiménez Hernández, que no logró reunir las 126, 395 (ciento veintiséis mil trescientos noventa y cinco) firmas, que representaban el 3\% de los 4,213,193 (Cuatro millones doscientos trece mil ciento noventa y tres) registrados en Lista Nominal con corte al 15 de diciembre (IEEP, 2016a). Jiménez entregó 147, 906 (Ciento cuarenta y siete mil novecientos seis) cédulas y de la revisión únicamente se encontraron en Lista Nominal 86, 019 (Ochenta y seis mil diecinueve) siendo insuficientes para otorgarle el registro (IEEP, 2016b). Los otros casos ya fueron mencionados en el apartado anterior y se pueden consultar en la Tabla 2.

En resumen, de los 40 ACI que no obtuvieron su registro, 31 (77.5\%) se debió a que entregaron un número menor de cédulas de respaldo requeridas, $1(2.5 \%)$ a que no las entregó, cinco (12.5\%) a que no presentaron la solicitud con la documentación correspondiente y $3(7.5 \%)$ a otras causas señaladas en la Tabla 2 . De los tres requisitos que obstaculizaron el registro de los ACI el más importante: la dificultad para recabar el número de cédulas de apoyo ciudadano; los ACIs ante la imposibilidad de contar con el número de firmas solicitadas desistían a su aspiración y no acudían ante el órgano electoral a entregar su solicitud de registro porque esta debía estar acompañada de la totalidad de las cédulas (CGIEEP, 2016).

Lo anterior es posible inferirlo de notas de prensa, en el caso de Villa, él declinó 14 días antes de que venciera el plazo para entregar las cédulas de apoyo ciuda- 
dano y manifestó su apoyo al ACI Ricardo Jiménez (Pineda y García, 2016), sin embargo, no entregó su desistimiento al IEEP motivo por el cual aparece como "no registrado" por falta de entrega de solicitud.

Por otra parte, Mazatle no logró reunir las cuatro mil firmas diarias que necesitaba para recabar las 126, 395 (ciento veintiséis mil trescientos noventa y cinco) cédulas de respaldo requeridas por el órgano electoral (Juárez, 2016), probablemente esto motivó que no se presentara a entregar su solicitud. Pozos, señaló que no acudió por un "asunto familiar" pero que su apoderado legal se presentó a ratificar su postura (Llaven, 2016), lo cual no está asentado en ningún acuerdo del órgano electoral. Villa, Jiménez, Mazatle, Hernández y López admitieron que les era imposible llegar a la meta, refiriéndose al número de cédulas (Ecooss, 2016, pp. 19-20).

En sintesis, la causa de "no registro" que más afecta a los ACIs es el reunir el número de cédulas de apoyo ciudadano solicitadas por el órgano electoral. Esto ha generado que sean pocos los aspirantes a una CI y más pocos aun los que logran el registro.

\section{Tabla 2: Causas de "no registro" de los ACIs de 2015 a 2020}

\begin{tabular}{|c|c|c|c|c|c|c|c|c|c|c|c|}
\hline No. & ACIs & CI & NEC & NES & Otro & No. & ACIs & CI & NEC & NES & Otro \\
\hline 1 & Enrique Suarez del Real Díaz de León (1) & $\mathrm{x}$ & & & & 21 & Felipe Neri Espinoza Herrera (11) & $\mathrm{X}$ & & & \\
\hline 2 & José Alfredo Loredo Zarate (2) & $\mathrm{X}^{*}$ & & & & 22 & Margarita Torres Sansores (11) & $\mathrm{X}$ & & & \\
\hline 3 & Juan Manuel García López (3) & $\mathrm{x}$ & & & & 23 & Edwuin Palomino Sulub (11) & $\mathrm{X}$ & & & \\
\hline 4 & Zenén Ávila Elena (4) & $\mathrm{x}$ & & & & 24 & Simón Soto Hernández (12) & $\mathrm{X}$ & & & \\
\hline 5 & Matías Romero Solano (5) & & $\mathrm{X}$ & & & 25 & Marisol Hernández Gómes (12) & & & & c) \\
\hline 6 & Ricardo Jiménez Hernández (6) & $\mathrm{x}$ & & & & 26 & Ariosto Genel García (13) & $\mathrm{X}$ & & & \\
\hline 7 & Ricardo Villa Escalera (6) & & & $\mathrm{X}$ & & 27 & Yolanda Gutiérrez Neri (13) & $\mathrm{X}$ & & & \\
\hline 8 & Marco Antonio Mazatle (6) & & & $\mathrm{X}$ & & 28 & Mario Rojas Alba (13) & $\mathrm{X}$ & & & \\
\hline 9 & Rubén Hernández Pérez (6) & & & $\mathrm{X}$ & & 29 & Luis Sergio Hernández Coronado (13) & $\mathrm{X}$ & & & \\
\hline 10 & Leodegario Pozos Vergara "El Tigre de la Sierra" (6) & & & $\mathrm{x}$ & & 30 & Edgar Francisco Flores Miranda (13) & $\mathrm{X}$ & & & \\
\hline 11 & Carolina López López (6) & & & $\mathrm{X}$ & & 31 & José Antonio Sandoval Tajonar (13) & $\mathrm{X}$ & & & \\
\hline 12 & Germán Maltos Reyna (7) & & & & a) & 32 & Temoc Ávila Hernández (14) & $\mathrm{X}$ & & & \\
\hline 13 & Isidro Pastor Medrano (8) & & & & b) & 33 & Sergio Arturo Fernández Herrera (14) & $\mathrm{X}$ & & & \\
\hline 14 & Enrique Cárdenas Sánchez (9) & $\mathrm{x}$ & & & & 34 & Arturo Marín Corona (14) & $\mathrm{X}$ & & & \\
\hline 15 & José Jorge Morales Alducín (9) & $\mathrm{X}$ & & & & 35 & Felipe Daniel Ruanova Zarate (14) & $\mathrm{X}$ & & & \\
\hline 16 & Israel de Jesús Ramos González (9) & $\mathrm{x}$ & & & & 36 & Israel de Jesús Ramos González (15) & $\mathrm{X}$ & & & \\
\hline 17 & Lenin Ostilio Urbina Trujillo (10) & $\mathrm{X}^{*}$ & & & & 37 & Erick Martínez Salazar (15) & $\mathrm{X}$ & & & \\
\hline 18 & Jorge Aramando Padilla Valvidia (10) & $\mathrm{x}$ & & & & 38 & Miguel Ángel Ocampo Hernández (15) & $\mathrm{X}$ & & & \\
\hline 19 & Horacio Culebro Borrayas (10) & $\mathrm{X}$ & & & & 39 & Juan Alejandro Amorós Herrera (15) & $\mathrm{X}$ & & & \\
\hline 20 & Sofía Castro Romero (11) & $\mathrm{X}^{*}$ & & & & 40 & Raymundo López Ortiz (15) & $\mathrm{X}$ & & & \\
\hline & $\begin{array}{l}\text { Total parcial } \\
\text { Total general }\end{array}$ & $\frac{12}{31}$ & $\frac{1}{1}$ & $\frac{5}{5}$ & $\frac{2}{3}$ & & Total parcial & 19 & 0 & 0 & 1 \\
\hline
\end{tabular}

Notas: $\mathrm{ACI}=$ Aspirantes a Candidatos Independientes, $\mathrm{CI}=$ Cédulas Insuficientes, $\mathrm{NEC}=$ No entrego cédulas, NES= No entrego solicitud. a) Se le negó el registro por no presentar cuenta bancaría a nombre de una asociación civil, ya que presentó el número de cuenta como persona física; b) Revocación de la CI por el Tribunal Electoral del Estado de México;* Firmas con irregularidades; c) Arrestada por presunto secuestro de un menor. Fuentes: elaboración propia con datos de (1) CEEPACSLP, 2015a; (2) CEEPACSLP, 2015b; (3) IEEPCO, 2016b; (4) Sánchez, 2016; (5) NVI, 2016; (6) IEEP, 2016b; (7) IEC, 2020; (8) IEEM, 2020; (9) IEEP, 2020; (10) IEPCCH, 2020; (11) IEPCY, 2020; (12) IEV, 2020; (13) IMPEPAC, 2020; (14) IEEBC, 2020; y (15) IEEP, 2020. 


\section{PORCENTAJES Y PLAZOS PARA SOLICITAR EL APOYO CIUDADANO}

Las legislaciones locales, en México, en materia político-electoral no son homogéneas; por lo que registrarse como CI en algunos estados es más difícil que en otros. Para probarlo se analizaron las legislaciones (en materia electoral) de 21 de los estados que tuvieron elecciones para gobernador entre 2015 y 2020, principalmente en dos aspectos: el porcentaje de apoyo ciudadano requerido y el tiempo para recabarlo. Con los datos recabados se elaboró la Tabla 3.

Así el porcentaje de cédulas de apoyo ciudadano requerido oscila entre el uno y el cinco por ciento de la Lista Nominal de Electores o del Padrón Electoral. El Estado que más porcentaje solicita es Aguascalientes con el 5\%, seguido de Baja California Sur con el 4\%. Doce estados solicitan el 3\%: Colima, Guerrero, Nuevo León, Sonora, Chihuahua, Durango, Hidalgo, Puebla, Quintana Roo, Tamaulipas, Tlaxcala y Veracruz. Querétaro requiere el 2.5\%, y cinco estados el 2\%: Campeche, Michoacán, San Luis Potosí, Oaxaca y Sinaloa. Zacatecas es el Estado que requiere el menor porcentaje: $1 \%$.

En cuanto al plazo para recabar el apoyo ciudadano, éste oscila entre 60 y 18 días. Seis estados son los que otorgan un mayor plazo, 60 días: Baja California Sur, Guerrero, San Luis Potosí, Hidalgo, Oaxaca y Veracruz. Les sigue Nuevo León con 50 días. Tres estados señalan 45 días: Chihuahua, Durango y Sinaloa. Seis estados fijan 40 días: Campeche, Sonora, Aguascalientes, Tamaulipas, Tlaxcala y Zacatecas. En cuatro estados se estipulan 30 días: Colima, Michoacán, Querétaro y Puebla. El Estado que menos plazo otorga es Quintana Roo con 18 días (si el año de la elección es bisiesto se agrega un día).

De acuerdo con los porcentajes de apoyo ciudadano requerido por cada estado se establecieron seis grupos, en el grupo uno se ubica el Estado que más porcentaje solicito (5\%, siendo más difícil el registro), y en el seis el grupo que menos porcentaje requirió (1\%, haciendo más fácil su registro): Grupo 1 (5\%), Aguascalientes; Grupo 2 (4\%), Baja California Sur; Grupo 3 (3\%), Colima, Guerrero, Nuevo León, Sonora, Chihuahua, Durango, Hidalgo, Puebla, Quintana Roo, Tamaulipas, Tlaxcala y Veracruz; Grupo 4 (2.5\%), Querétaro; Grupo 5 (2\%), Campeche, Michoacán, San Luis Potosí, Oaxaca y Sinaloa; Grupo 6 (1\%), Zacatecas.

Por lo que respecta al plazo para recabar el apoyo ciudadano requerido por cada estado se establecieron seis grupos, en el grupo uno se ubica el Estado que menos plazo otorgó (18 días, siendo más difícil el registro), y en el seis el grupo que más plazo dio (60 días, haciendo más fácil su registro). Grupo 1 (18 días), Quintana Roo; Grupo 2 (30 días), Colima, Michoacán, Querétaro y Puebla; Grupo 3 (40 días), Campeche, Sonora, Aguascalientes, Tamaulipas, Tlaxcala y Zacatecas; Grupo 4 (45 días), Sinaloa, Chihuahua y Durango; Grupo 5 (50 días), Nuevo León; Grupo 6 (60 días), Baja California Sur, Guerrero, San Luis Potosí, Hidalgo, Oaxaca y Veracruz. 
Para relacionar ambas variables (porcentaje y plazo) se sumó, por estado, su grupo de porcentaje a su grupo de plazo y se dividió entre dos (que es el número de variables analizadas); obteniendo así el promedio general que oscila entre 2 y 5.5 , donde: 2 representa una mayor dificultad para obtener el registro como CI debido a que el porcentaje de apoyo requerido es alto y el plazo corto, y 5.5 establece una menor dificultad para obtener el registro como CI debido a que el porcentaje de apoyo requerido es bajo y el plazo para obtenerlo es más amplio. Con los resultados obtenidos se establecieron cuatro rangos de acuerdo con la dificultad para obtener el registro:

- Registro muy difícil (2.0 y 2.5 en promedio), 4 estados: dos con 2.0, Aguascalientes y Quintana Roo; y dos con 2.5, Colima y Puebla.

- Registro difícil (3.0 y 3.5 en promedio), 7 estados: cuatro con 3.0, Sonora, Tamaulipas, Tlaxcala y Querétaro; y tres con 3.5, Chihuahua, Durango y Michoacán;

- Registro medianamente difícil (4.0 y 4.5 en promedio), 8 estados: tres con 4.0, Baja California Sur, Nuevo León y Campeche; y cinco con 4.5, Guerrero, Hidalgo, Veracruz, Sinaloa y Zacatecas.

- Registro poco difícil (5.0 y 5.5 en promedio), 2 estados: ninguno con 5.0 y dos con 5.5: San Luis Potosí y Oaxaca.

De los 21 estados estudiados, Aguascalientes y Quintana Roo son los estados donde es más difícil registrarse como CI seguidos de Colima y Puebla, ya que se requiere reunir altos porcentajes de apoyo ciudadano en un plazo corto de tiempo; por su parte San Luis Potosí y Oaxaca son los estados en los que registrarse como CI es menos difícil, ya que se requiere reunir un porcentaje de apoyo más bajo en un tiempo más largo. En ninguno de los cuatro rangos establecidos se señala que el registro de CI sea fácil toda vez que reunir el porcentaje de apoyo ciudadano requerido en los plazos establecidos resulta una ardua tarea para cualquier candidato que no está apoyado por un partido político.

De acuerdo con las variables analizadas (porcentaje y plazo) es difícil que los ciudadanos puedan registrarse como CI, de ahí que sea necesario trabajar en cuatro aspectos: a) adecuar la normatividad flexibilizando los requisitos para que los ciudadanos participen como CI, b) homologar los requisitos entre las diferentes entidades, c) capacitar a los ciudadanos interesados sobre los requisitos y tiempos establecidos para obtener su registro como CI, y d) hacer los ajustes necesarios para que compitan en equidad con los candidatos de partido.

\section{Tabla 3: Apoyo ciudadano para la elección de gobernador (porcentajes y plazos)}

\begin{tabular}{c|c|c|c|c|c} 
Estado & Porcentaje & Plazo (en días) & Estado & Porcentaje & Plazo (en días) \\
\hline Baja California Sur & $4 \%$ LN (1) & 60 & Aguascalientes & $5 \%$ LN (10) & 40 \\
\hline Campeche & $2 \%$ LN (2) & $40(22)$ & Chihuahua & $3 \%$ LN (11) & 45 \\
\hline Colima & $3 \%$ PE (3) (a) & 30 & Durango & $3 \%$ LN (12) & 45 \\
\hline Guerrero & $3 \%$ LN (4) & $60(23)$ & Hidalgo & $3 \%$ LN (13) & 60 \\
\hline Michoacán & $2 \%$ LN (5) & 30 & Oaxaca & $2 \%$ LN (14) & 60 \\
\hline Nuevo León & $3 \%$ LN (6) & $50(24)$ & Puebla & $3 \%$ LN (15) & 30 \\
\hline
\end{tabular}




\begin{tabular}{c|c|c|c|c|c}
\hline Estado & Porcentaje & Plazo (en días) & Estado & Porcentaje & Plazo (en días) \\
\hline Querétaro & $2.5 \% \mathrm{LN}(7)$ & 30 & Quintana Roo & $3 \%$ PE (16) (a) & $18 / 19^{*}$ \\
\hline San Luis Potosí & $2.0 \% \mathrm{LN}(8)(\mathrm{a})$ & 60 & Sinaloa & $2 \% \mathrm{LN}(17)$ & 45 \\
\hline Sonora & $3.0 \% \mathrm{LN}(9)(\mathrm{a})$ & 40 & Tamaulipas & $3 \% \mathrm{LN}(18)$ & 40 \\
\hline & & & Tlaxcala & $3 \% \mathrm{LN}(19)$ & 40 \\
\hline & & & Veracruz & $3 \% \mathrm{LN}(20)$ & 60 \\
\hline & & & Zacatecas & $1 \% \mathrm{LN}(21)$ & 40 \\
\hline
\end{tabular}

Fuentes: elaboración propia con datos de (1) (LEEBCS, 2014: art. 194), (2) (LIPEEC, 2014, art.182, fracción I), (3) (CEEC, 2014, art. 345, fracción II), (4) (LIPEEGPL, 2014, art. 39, párr. 1), (5) (CEEMO, 2016, 314, fracción IV, a), (6) (EEENL, 2014, art. 204), (7) (LEEQR, 2014, art. 222, fracciones I y III), (8) (LEESLP, 2014, art. 237, fracción II), (9) (LIPEES, 2014, art. 9), (10) (CEEA, 2015, art. 376, fracción I), (11) (LEEC, 2015, art. 205, párr. 1, inciso a), (12) (LIPEED, 2014, art. 301, párr. 1), (13) (CEEH, 2014, art. 228), (14) (LIPEEO, 2015, art. 93, párr. 1), (15) (CIPEEP, 2016, art. 201 quater, fracción I, inciso a), (16) (LEEQR, 2015, art. 134, fracciones II-IV), (17) (LIPEES, 2015, art. 83, párr. 1), (18) (LEET, 2015, arts. 10 y 18, párr. 1), (19) (LIPEET, 2015, art. 299, párr. 1), (20) (CEEV, 2015, art. 269, párr. 1), (21) (LEEZ, 2015, art. 322, párr. 1), (22). (CGIEEC, 2014, 10), (23) (IEPCEG, 2014,7), (24) (LEENL, 2014: art. 19). Notas: LN, Lista Nominal; PE, Padrón Electoral. (a) Sólo se registrará como CI el ACI que más apoyo obtuvo. *2016 fue año bisiesto, por ello a los plazos señalados con fechas de febrero se les sumo un día; para años ordinarios restar un día.

\section{IMPACTO DE LAS CANDIDATURAS INDEPENDIENTES EN EL ÁMBITO LOCAL}

En 2015 nueve estados celebraron elecciones para elegir Gobernador, en cinco de ellas ganó el PRI: Campeche (en coalición con el PVEM), Colima (en elecciones extraordinarias en coalición con PVEM, PT y NA), Guerrero (en coalición con el PVEM), San Luis Potosí y Sonora (en coalición con el PVEM y NA); esta ganancia representa el $55.5 \%$ del total de los estados en disputa, constituyéndose como el partido que más gubernaturas obtuvo en dicha elección. El PAN obtuvo el triunfo en dos estados: Baja California Sur (en coalición con el PRS) y Querétaro, estos representan el 22.2\% de los estados; por tanto, el PAN se adjudicó el segundo puesto. En tercer lugar, se ubicaron el PRD y un I, ambos obtuvieron el triunfo en un Estado cada uno: el PRD en Michoacán (en coalición con PT y NA), y el I en Nuevo León; en ambos casos su triunfo representa el $11.1 \%$ de los estados en disputa.

En 2016, 12 estados celebraron elecciones locales para elegir Gobernador, en 5.5 de ellos ganó el PAN: Aguascalientes; Chihuahua; Durango, Quintana Roo y Veracruz (en coalición con el PRD), así como Puebla (en coalición con el PT). Esto representó el $45.8 \%$ de los estados en disputa, colocándose en primer lugar. El segundo lugar fue para el PRI que ganó en cinco estados: Hidalgo, Oaxaca, Sinaloa, Tlaxcala y Zacatecas, lo que representó el $41.6 \%$ del total de las gubernaturas. Por otra parte, el PRD no obtuvo estados solo, únicamente ganó el equivalente al 1.5 de los estados, ya que como se mencionó en tres estados obtuvo el triunfo en coalición con el PAN; lo que represento el $12.5 \%$ de los estados. En esta elección ninguno de los 10 CI registrados obtuvo la gubernatura.

En 2017, tres estados celebraron elecciones locales para elegir Gobernador, en 
dos de ellos ganó el PRI (66.66\%) en coalición con otros partidos y en uno de ellos el PAN (33.33\%)también en coalición. En esta elección ninguno de los 6 CI registrados obtuvo la gubernatura. En las elecciones de 2018, ocho estados eligieron a su Gobernador, en cuatro de ellos ganó Morena en coalición con otros partidos (50\%), seguido del PAN que en coalición ganó en tres de ellos (37.5\%); MC ganó en uno de los Estados (12.5 \%). Ninguno de los tres CI registrados obtuvo una gubernatura.

Durante 2019, solo se celebraron dos elecciones (una ordinaria y una extraordinaria) para elegir Gobernador: en ambas gano Morena en coalición con otros partidos (100\%). En 2020 no se celebraron en el primer semestre del año elecciones para gobernador ni se tienen programadas elecciones para lo que resta del año. Para esta elección no hubo CI registrados.

En total entre 2015 y 2020 se han realizado 35 elecciones locales para elegir Gobernador (33 ordinarias y 2 extraordinarias), en 13 de ellas ganó el PAN (38.23\%), en 12 el PRI (35.29\%), en 6 Morena (17.64\%), en una el PRD (2.94\%); todos los anteriores en coalición con otros partidos, por su parte, MC obtuvo una gubernatura (2.94\%) y solo un CI logró ganar la elección en un Estado (2.94\%).

De acuerdo con lo anterior, quién más triunfos ha obtenido es el PAN, seguido muy de cerca por el PRI; después Morena, y por último empatan MC, PRD y un CI (ver Tabla 4). Cabe destacar que el PRI no ganó. Ninguna gubernatura en las elecciones de 2018 y 2019, por lo que se observa un descenso de dicho partido, sin embargo, Morena ganó 4 (50\%) de las 8 gubernaturas en disputa en 2018 y las dos elecciones celebradas en 2019 (100\%), lo que representa un crecimiento importante para dicho partido. En resumen, de las 34 gubernaturas en disputa: 33 (97.05\%) las han ganado los partidos políticos y solo una un CI (2.94\%), por lo que el impacto de las CI es muy bajo frente al sistema de partidos mexicano.

Para medir el impacto de las CI en el sistema de partidos mexicano, se establecieron tres rangos: alto, medio y bajo. Los rangos se elaboraron restando al porcentaje más alto obtenido por un partido y/o CI (38.23\%) al más bajo (2.94\%), lo que dio como resultado $35.29 \%$, este porcentaje se dividió entre tres para establecer los rangos, obteniendo el común divisor de 11.7\%. Los rangos quedaron así:

-Alto impacto: cuando un partido y/o CI obtiene entre el $38.23 \%$ y el $26.53 \%$ de los estados en disputa.

-Impacto medio: cuando un partido y/o CI obtiene menos del $26.53 \%$ y hasta el $14.83 \%$ de las gubernaturas posibles.

-Bajo impacto: cuando un partido y/o CI obtiene menos del 14.83\%.

De acuerdo con estos rangos el PRI y el PAN se ubicaron en alto impacto, Morena en impacto medio y el PRD, MC y CI en bajo impacto. Sin embargo, se observa una tendencia al descenso a bajo impacto del PRI así como un ascenso a alto impacto de Morena de acuerdo con los datos de las elecciones de 2018 y 2019.

Por lo tanto, las CI tuvieron un bajo impacto en el sistema de partidos mexica- 
nos toda vez que no lograron un porcentaje importante de las gubernaturas en disputa entre 2015 y 2020.

Estos resultados ponen de manifiesto que si bien, la introducción "legal” de las CI representan un cambio en el sistema de partidos mexicano, en su aplicación "real" su impacto ha sido muy bajo. De no hacerse las reformas necesarias el impacto de las $\mathrm{CI}$ en el sistema de partidos seguirá siendo bajo, porque es difícil que los ciudadanos logren su registro como CI y más aún que ganen la gubernatura toda vez que compiten en situación de desventaja con los candidatos de partido.

\section{Tabla 4: Resultados de elecciones de Gobernador (2015-2020)}

\begin{tabular}{|c|c|c|c|c|c|}
\hline No. & 2015 (7 de junio) & Ganador & No. & 2017 (7 de julio) & Ganador \\
\hline 1 & Baja California Sur (1) & PAN/PRS & 1 & Coahuila (22) & PRI/PVEM/NA/PSDI/PI/PRC/PCP \\
\hline 2 & Campeche (2) & PRI/PVEM & 2 & Nayarit (23) & PAN/PRD/PT/PRS \\
\hline 3 & Colima $(3)^{*}$ & PRI/PVEM/NA (Anulada) & \multirow{2}{*}{3} & \multirow{2}{*}{ Estado de México (24) } & \multirow{2}{*}{ PRI/PVEM/NA/PE S } \\
\hline 4 & Colima $(3)^{* *}$ & PRI/PVEM/PT/NA & & & \\
\hline 5 & Guerrero (4) & PRI/PVEM & No. & 2018 (1 de julio) & Ganador \\
\hline 6 & Michoacán (5) & $\mathrm{PRD} / \mathrm{PT} / \mathrm{NA}$ & 1 & Jalisco (25) & MC \\
\hline 7 & Nuevo León (6) & I & 2 & Guanajuato (26) & PAN/PRD/MC \\
\hline 8 & Querétaro (7) & PAN & 3 & Puebla (27) & PAN/PRD/MC \\
\hline 9 & San Luis Potosí (8) & PRI & 4 & Tabasco (28) & Morena/PT/PES \\
\hline 10 & Sonora (9) & PRI/PVEM/NA & 5 & Chiapas (29) & Morena/PT/PES \\
\hline No. & 2016 (5 de junio) & Ganador & 6 & Yucatán (30) & PAN/PRD/MC \\
\hline 1 & Aguascalientes (10) & PAN & 7 & Veracruz (31) & Morena/PT/PES \\
\hline 2 & Chihuahua (11) & PAN & 8 & Morelos (32) & Morena/PT/PES \\
\hline 3 & Durango (12) & PAN/PRD & No. & 2019 (5 de junio) & Ganador \\
\hline 4 & Hidalgo (13) & PRI & 1 & Baja california (33) & Morena/PT/PES \\
\hline 5 & Oaxaca (14) & PRI & 2 & Puebla (Extraordinaria)(34) & Morena/PT/PVEM \\
\hline 6 & Puebla (15) & $\mathrm{PAN} / \mathrm{PT}$ & No. & 2020 (sin elecciones) & Ganador \\
\hline 7 & Quintana Roo (16) & PAN/PRD & 0 & -- & -- \\
\hline 8 & Sinaloa (17) & PRI & & & \\
\hline 9 & Tamaulipas (18) & PAN & & & \\
\hline 10 & Tlaxcala (19) & PRI & & & \\
\hline 11 & Veracruz (20) & PAN/PRD & & & \\
\hline 12 & Zacatecas (21) & PRI & & & \\
\hline
\end{tabular}

Nota: * Empate técnico, se anula la elección y se convoca a elecciones extraordinarias, ${ }^{* *}$ Se celebró elección extraordinaria el 17 de enero de 2016. Fuentes: elaboración propia con datos de (1) IEEBCS, 2016; (2) IEEC, 2016; (3) IEECO, 2016; (4) IEPCEG, 2016; (5) IEM, 2016; (6) CEENL,2016; (7) IEEQ, 2016; (8) CEEPACSLP, 2016; (9) IEEPACS, 2016; (10) IEEA, 2016; (11) IEECH, 2016; (12) IEPCD, 2016; (13) IEEH, 2016; (14) IEEPCO, 2016a; (15) IEEP, 2016; (16) IEQR, 2016; (17) IEES, 2016; (18) IETAM, 2016; (19) IETLAX, 2016; (20) IEV , 2016; (21) IEEZ, 2016; (22) IEEC, 2020; (23) IEEN, 2020; (24) IEEM, 2020; (25) IEPCJ, 2020; (26) IEEG, 2020; (27) IEEP, 2020; (28) IEPCT, 2020; (29) IEPCCH, 2020; (30) IEPCY, 2020; (31) IEV, 2020; (32) IMPEPAC, 2020; (33) IEEBC, 2020; y (34) IEEP, 2020. 


\section{REFLEXIONES FINALES}

Los CIs no son de reciente implementación en México, ya que han estado presentes en la historia política del país desde su independencia; sin embargo, durante casi todo el periodo del régimen del partido hegemónico desaparecieron de la escena electoral. La reciente reintroducción de las CIs (2012) se realizó en un nuevo régimen: el democrático, el cual permite "legalmente" el acceso al poder a los ciudadanos; sin embargo, el acceso "real" no garantiza las condiciones de igualdad y equidad en la contienda entre los CIs y los candidatos de partido. La implementación de los CIs constituye un avance en el acceso al poder de los ciudadanos, pero la normatividad aplicada hasta hoy no es suficiente para garantizar que los ciudadanos accedan realmente a los cargos de elección popular.

Las CIs retornaron a la escena política para hacer frente a la crisis del sistema de partidos mexicano, ya que la desconfianza de los ciudadanos hacia los partidos políticos es alta (Latinobarometro, 2016). Dicha desconfianza derivó de las políticas públicas poco exitosas implementadas por los gobiernos en turno (tanto priistas como panistas) para hacer frente a las demandas ciudadanas, y que en algunos casos tuvieron resultados adversos. Esto debido a que los partidos políticos para obtener el voto de los ciudadanos hicieron promesas durante sus campañas electorales para erradicar, o por lo menos disminuir, los problemas que aquejaban (y aquejan) a la ciudadanía, pero al llegar al poder dichas promesas no se cumplieron; esto incremento la desconfianza en los partidos políticos y sus candidatos.

La alternancia no resolvió las demandas ciudadanas y se hizo necesario reintroducir las CIs. Así entre 2015 y 2020 se realizaron elecciones locales para elegir gobernador en los 31 Estados de la República Mexicana a través de 35 elecciones (33 ordinarias y dos extraordinarias), en ellas se registró un bajo número de ACIs (61), y más bajo aún el número de CIs que lograron su registro (21); de estos solo un CI logró ganar la gubernatura de un Estado: Nuevo León.

Las causas principales que originaron que 40 de los ACIs no obtuvieran su registro como CI fueron tres: insuficiente número de cédulas de apoyo ciudadano recabadas (31), falta de entrega de la solicitud con los documentos requeridos (5) y falta de entrega de las cédulas (1), a estas se sumaron otras causas: (3) presentar cuenta bancaria como persona física debiendo ser a nombre de una asociación civil, revocación de la CI por el Tribunal debido a la entrega de firmas con irregularidades y arresto por presunción de la realización de un delito. Estás causas de "no registro" están relacionadas principalmente con dos requisitos para ser registrado como CIs: a) él (gran) porcentaje de apoyo ciudadano requerido a través de cédulas y b) él (corto) plazo para recabar el apoyo ciudadano.

Cada Estado determina el porcentaje y plazos para recabar el apoyo ciudadano lo que hace que en algunos estados sea más difícil reunir los requisitos para ser CI que en otros, además de que en Estados como Tabasco solo se permite registrar a un CI (el que obtenga el mayor número de cédulas y que rebase el mínimo solicitado). Así los 
porcentajes de apoyo varían entre el $1 \%$ y el $5 \%$, los plazos entre 18 y 60 días, lo que amplía la brecha de desigualdad entre los CIs de acuerdo con los requisitos legales que se establezcan en su respectivo Estado. Así Aguascalientes es el Estado donde es más difícil registrarse como CI ya que se requiere reunir el 5\% de apoyo ciudadano en un plazo de 40 días; por su parte San Luis Potosí y Oaxaca son los estados en los que registrarse como CI es menos difícil ya que se requiere reunir el $2 \%$ de apoyo ciudadano en un plazo de 60 días.

En ninguno de los estados es fácil registrarse como CI, ya que reunir el porcentaje de apoyo ciudadano requerido en los plazos establecidos resulta complicado para cualquier candidato que no es apoyado por un partido político.

Ahora bien, de los resultados de las elecciones locales celebradas entre 2015 y 2020 para elegir gobernador se desprende que en 13 de ellas ganó el PAN (38.23\%), en 12 el PRI (35.29\%), en 6 Morena (17.64\%), en una el PRD (2.94\%); todos los anteriores en coalición con otros partidos, por su parte, MC obtuvo una gubernatura (2.94\%) y solo un CI logró ganar la elección en un Estado (2.94\%).

Con los resultados anteriores se establecieron tres rangos (alto, medio y bajo) para medir el impacto de las CI y de cada uno de los partidos políticos en el sistema de partidos mexicano, obteniendo que: el PRI y el PAN se ubicaron en alto impacto, Morena en impacto medio y el PRD, MC y CI en bajo impacto. Sin embargo, se observa una tendencia al descenso a bajo impacto del PRI así como un ascenso a alto impacto de Morena de acuerdo con los datos de las elecciones de 2018 y 2019. En total, de las 34 gubernaturas en disputa: 33 (97.05\%) las han ganado los partidos políticos y solo una un CI (2.94\%), por lo tanto, las CI tuvieron un bajo impacto en el sistema de partidos mexicano toda vez que no lograron un porcentaje importante de las gubernaturas en disputa entre 2015 y 2020.

Por lo tanto, la implementación de las CIs representa un cambio en el sistema de partidos mexicano, así como un avance en el acceso al poder por parte de los ciudadanos; sin embargo, en su ejecución su impacto ha sido muy bajo. Para incrementar el impacto de las CIs frente a los partidos políticos es necesario hacer más flexibles los requisitos para que los ciudadanos se registren como CI, sobretodo en cuanto al porcentaje de apoyo ciudadano y los plazos para obtenerlo, esto incrementará el número de ACIs y de CIs ampliando así la competencia.

También es importante homologar los requisitos entre las diferentes entidades, para que se garantice el acceso igualitario y equitativo al registro por parte de todos los ciudadanos. Así mismo, los órganos electorales deben capacitar a los ciudadanos interesados en registrarse como CIs con respecto a los requisitos y tiempos establecidos para obtener su registro. Finalmente es ineludible hacer los ajustes necesarios, tanto en la normatividad como en la práctica, para que los CIs y los candidatos de partido compitan en condiciones de equidad. 


\section{REFERENCIAS}

1. Borja, R. (2002). Enciclopedia de la política. Distrito Federal, México: FCE.

2. Boudon, L. (01 de enero de 1998). Los partidos y la crisis de representación en América Latina: los casos de Colombia, México y Venezuela. Contribuciones (15), pp. 7-28.

3. Castellanos, R. (2014). La Reforma Político Electoral de 2014. Ciudad de México, México: Senado de la República LXIII Legislatura/Instituto Belisario Domínquez.

4. Comisión Estatal Electoral Nuevo León (CEENL). (Consultado 22 de noviembre de 2016). Disponible en: https://www.ceenl.mx/

5. Consejo Estatal Electoral de Participación Ciudadana de San Luis Potosí (CEEPACSLP). (Consultado el 22 de noviembre de 2016). Disponible en: http://www.ceepacslp.org.mx/

6. Consejo Estatal Electoral de Participación Ciudadana de San Luis Potosí (CEEPACSLP). $\left(2015^{\mathrm{a}}\right.$ ). Resolución definitiva del expediente del C. Enrique Suarez del Real Díaz de León. San Luis Potosí: CEEPACSLP.

7. Consejo Estatal Electoral de Participación Ciudadana de San Luis Potosí (CEEPACSLP). (2015b). Resolución definitiva del expediente del C. José Alfredo Loredo Zarate. San Luis Potosí: CEEPACSLP.

8. Consejo General del Instituto Electoral del Estado de Puebla (CGIEEP). (2016). CG/AC037/16 Acuerdo del Consejo General del Instituto Electoral del Estado, por el que emite criterios respecto del artículo 19 de los lineamientos dirigidos a los (as) ciudadanos (as) que deseen contender como candidatos (as) independientes al cargo de gobernador del Estado de Puebla para el proceso electoral estatal ordinario 2015-2016. Puebla de Zaragoza: CGIEEP.

9. Ecooss y expresión. Semanario de Política, Análisis e Información General (Ecooss). (21 de marzo de 2016). Independientes se confrontan por 'piso disparejo' en Puebla. Ecooss (26).

10. González, M. (02 de marzo de 2010). Candidaturas independientes. Ensayo. Biblioteca Jurídica Virtual, pp.43-58.

11. Hernández, M. (2012). La importancia de las candidaturas independientes. Cuadernos de Divulgación de la Justicia Electoral No. 12. Ciudad de México, México: TEPJF.

12. Instituto de Elecciones y Participación Ciudadana de Chiapas (IEPCCH). (Consultado el 2 de julio de 2020). Disponible en: https://www.iepc-chiapas.org.mx/

13. Instituto Electoral de Coahuila (IEC). (Consultado el 5 de julio de 2020). Disponible en: http://www.iec.org.mx/v1/ 
14. Instituto Electoral de Hidalgo (IEEH). (Consultado el 22 de noviembre de 2016). Disponible en: http://www.ieehidalgo.org.mx/

15. Instituto Electoral del Estado de México (IEEM). (Consultado el 4 de julio de 2020). Disponible en: https://www.ieem.org.mx/

16. Instituto Electoral de Michoacán (IEM). (Consultado el 23 de noviembre de 2016). Disponible en: http://www.iem.org.mx/

17. Instituto Electoral de Quintana Roo (IEQR). (Consultado el 22 de noviembre de 2016). Disponible en: http://www.ieqroo.org.mx/

18. Instituto Electoral de Tamaulipas (IETAM). (Consultado el 22 de noviembre de 2016). Disponible en: http://ietam.org.mx/portal/

19. Instituto Electoral de Tlaxcala (IETLAX). (Consultado el 22 de noviembre de 2016). Disponible en: http://www.ietlax.org.mx/

20. Instituto Electoral del Estado de Campeche (IEEC). (Consultado el 23 de noviembre de 2016). Disponible en: http://www.ieec.org.mx/

21. Instituto Electoral del Estado de Guanajuato (IEEG). (Consultado el 29 de junio de 2020). Disponible en: https://ieeg.mx/

22. Instituto Electoral del Estado de Puebla (IEEP) (2016b). CG/AC-042/16 Acuerdo del Consejo General del Instituto Electoral del Estado, por el que resuelve sobre diversas solicitudes de registro de aspirantes a candidatos y candidatas independientes para el proceso electoral estatal ordinario 2015-2016. Puebla de Zaragoza: IEEP.

23. Instituto Electoral del Estado de Puebla (IEEP). (Consultado el 22 de noviembre de 2016 ${ }^{\mathrm{a}}$ ). Disponible en: http://www.iee-puebla.org.mx/

24. Instituto Electoral del Estado de Puebla (IEEP). (Consultado el 3 de julio de 2020). Disponible en: http://www.iee-puebla.org.mx/

25. Instituto Electoral del Estado de Querétaro (IEEQ). (Consultado el 22 de noviembre de 2016). Disponible en: http://ieeq.mx/

26. Instituto Electoral del Estado de Sinaloa (IEES). (Consultado el 22 de noviembre de 2016). Disponible en: http://www.cee-sinaloa.org.mx/publico/principal/index.aspx

27. Instituto Electoral del Estado de Zacatecas (IEEZ). (Consultado el 22 de noviembre de 2016). Disponible en: http://www.ieez.org.mx/

28. Instituto Electoral y de Participación Ciudadana del Estado de Durango (IEPCD). (Consultado el 22 de noviembre de 2016). Disponible en: http://www.iepcdgo.org.mx/ 
29. Instituto Electoral y de Participación Ciudadana del Estado de Guerrero (IEPCEG). (Consultado el 22 de noviembre de 2016). Disponible en: http://www.iepcgro.mx/

30. Instituto Electoral y de Participación Ciudadana de Jalisco (IEPCJ). (Consultado el 30 de junio de 2020). Disponible en: http://www.iepcjalisco.org.mx/

31. Instituto Electoral y de Participación Ciudadana de Tabasco (IEPCT). (Consultado el 30 de junio de 2020). Disponible en: http://iepct.mx/

32. Instituto Electoral y de Participación Ciudadana de Yucatán (IEPCY). (Consultado el 2 de julio de 2020). Disponible en: http://www.iepac.mx/

33. Instituto Estatal de Veracruz (IEV). (Consultado el 22 de noviembre de 2016). Disponible en: https://oplever.org.mx/index.html

34. Instituto Estatal de Veracruz (IEV). (Consultado el 2 de julio de 2020). Disponible en: https://oplever.org.mx/index.html

35. Instituto Estatal Electoral de Aguascalientes (IEEA). (Consultado el 23 de noviembre de 2016). Disponible en: http://www.ieeags.org.mx/

36. Instituto Estatal Electoral de Baja California (IEEBC). (Consultado el 2 de julio de 2020). Disponible en: https://www.ieebc.mx/

37. Instituto Estatal Electoral de Baja California Sur (IEEBCS). (Consultado el 22 de noviembre de 2016). Disponible en: http://www.ieebcs.org.mx/

38. Instituto Estatal Electoral de Chihuahua (IEECH). (Consultado el 22 de noviembre de 2016). Disponible en: http://www.ieechihuahua.org.mx/

39. Instituto Estatal Electoral de Colima (IEECO). (Consultado el 23 de noviembre de 2016). Disponible en: http://www.ieecolima.org.mx/

40. Instituto Estatal Electoral de Nayarit (IEEN). (Consultado el 2 de julio de 2020). Disponible en http://ieenayarit.org/

41. Instituto Estatal Electoral y de Participación Ciudadana de Oaxaca (IEEPCO). (Consultado el 22 de noviembre de 2016 ${ }^{\mathrm{a}}$ ). Disponible en: http://www.ieepco.org.mx/

42. Instituto Estatal Electoral y de Participación Ciudadana de Oaxaca (IEEPCO) (2016b). Acuerdo: IEEPCO-CG-36/2016, respecto de la solicitud de registro de candidato independiente a Gobernador del Estado, presentada por el ciudadano Juan Manuel García López, para el proceso electoral ordinario 2015-2016. Oaxaca de Juárez: IEEPCO.

43. Instituto Estatal Electoral y de Participación Ciudadana de Sonora (IEEPACS). (Consultado el 23 de noviembre de 2016). Disponible en: http://www.ieesonora.org.mx/ 
44. Instituto Morelense de Procesos Electorales y Participación Ciudadana (IMPEPAC). (Consultado el 1 de julio de 2020). Disponible en: http://impepac.mx/

45. Instituto Nacional de Estudios Políticos A.C. (INEP) (2002). Diccionario Electoral. D.F., México: Instituto Nacional de Estudios Políticos A.C.

46. Juárez, V.H. (18 de febrero de 2016). Mazatle por debajo de las firmas diarias para obtener registro. Cambio.

47. Latinobarómetro (2016). Latinobarómetro análisis de datos. Santiago de Chile: Latinobarómetro (Consultado el 2 de enero). Disponible en: http://www.latinobarometro.org/latOnline.jsp

48. Lizcano, F. y otros. ( 01 de enero de 2013). Calidad de la elección a gobernador del Estado de México en julio de 2011. Democracias (3), pp. 55-96.

49. Llaven, Y. (22 de marzo de 2016). Leodegario Pozos evidencia que su postulación es controlada por el gobierno estatal. La Jornada de Oriente.

50. Loaeza, S. y Segovia, R. (1987). La vida política mexicana en la crisis. Ciudad de México, México: El Colegio de México.

51. Maya. I. (15 de junio de 2016b). México: entre la desconfianza y el hartazgo ciudadano. Estudios de Política Exterior.

52. Maya. I. (2016ª). Ser candidato independiente en México ¿es fácil? Blog Hipótesis Alternativa. Salamanca: Universidad de Salamanca (Consultado el 26 de noviembre). Disponible en: http://blog.acpa-usal.com/?s=maya

53. Noticias, Voz e Imagen (NVI). (03 de marzo de 2016). Elección a gubernatura de Oaxaca. Sin independientes. NVI. Recuperado de: http://www.nvinoticias.com/content /elecci\%C3\%B3n-gubernatura-de-oaxaca-sin- independientes.

54. Nudelman, R. (2001). Diccionario de política latinoamericana del siglo XX. Distrito Federal, México: Oceano.

55. Observatorio de Elites Parlamentarias en América Latina (PELA) (2016). Series temporales: México. Salamanca, España: Universidad de Salamanca (Consultado el 10 de marzo). Disponible en: http://americo.usal.es/oir/elites/series_temporales.htm

56. Palazuelos, I. (01 de enero de 2012). La desconfianza en los partidos políticos y la percepción ciudadana de desempeño gubernamental: México ante América Latina. Revista Mexicana de Análisis Político y Administración Pública (1), pp. 79-107.

57. Paramio. L. (01 de enero de 1999). Estrategias partidarias y desconfianza política. Revista Internacional de Sociología (22), pp. 183-201. 
58. Pineda, M. y García, G. (29 de febrero de 2016). Ricardo Villa Escalera, primer independiente que tira el arpa. E-Consulta.com.

59. Reyes del C., J. (01 de julio de 1995). Las transformaciones del sistema electoral. Política y Cultura (5), pp. 7-27.

60. Sánchez, V. (01 de abril de 2016). Falsean independientes documentos. El Norte. Recuperado de:http://www.elnorte.com/aplicacioneslibre/articulo/default.aspx?id= 809177\&md5=91e400 9478b66097e2a11dd2e861917d\&ta=0dfdbac11765226904c16cb9 ad1b2efe (23 de noviembre).

61. Sartori, G. (2005). Parties and Party Systems. A framework for analysis. Colchester, UK: University of Oxford.

62. Zovatto, D. (2008). Regulación Jurídica de los Partidos Políticos en América Latina. Distrito Federal, México: IIJ-UNAM.

\section{Legislaciones}

63. Código de Instituciones y Procesos Electorales del Estado de Puebla (CIPEEP). Periódico oficial, Puebla de Zaragoza, 09 de enero de 2016.

64. Código Electoral del Estado de Colima (CEEC). Periódico oficial El Estado de Colima, Colima, 28 de junio de 2014.

65. Código Electoral del Estado de Hidalgo (CEEH). Periódico oficial, Pachuca de Soto, 30 de junio de 2014.

66. Código Electoral del Estado de Michoacán de Ocampo (CEEMO). Periódico oficial, Morelia, 29 de diciembre de 2016.

67. Código Electoral para el Estado de Aguascalientes (CEEA). Periódico oficial, Aguascalientes, 02 de marzo de 2015.

68. Código Electoral para el Estado de Veracruz de Ignacio de la Lave (CEEVILl). Periódico oficial, Xalapa, 30 de junio de 2015.

69. Consejo General del Instituto Electoral del Estado de Campeche (CGIEEC) (2014). Lineamientos para el Registro de Candidatos Independientes a Cargos de Elección Popular para el Proceso Electoral Estatal Ordinario 2014-2015. San Francisco Campeche: CGIEEC.

70. Constitución Política de los Estados Unidos Mexicanos (CPEUM). Diario Oficial de la Federación, Ciudad de México, México, 27 de mayo de 2015.

71. Ley Electoral y de Partidos Políticos del Estado de Tabasco (LEPPET). Periódico oficial, Vistahermosa, 02 de julio de 2014. 
72. Instituto Electoral y de Participación Ciudadana del Estado de Guerrero (IEPCEG) (2014). Lineamientos de Candidaturas Independientes, que deberán observar los ciudadanos interesados en participar como Candidatos Independientes en el Proceso Electoral Ordinario de Gobernador, Diputados y Ayuntamientos 2014-2015. Chilpancingo: IEPCEG.

73. Ley de Instituciones y Procedimientos Electorales del Estado de Campeche (LIPEEC). Periódico oficial, San Francisco de Campeche, 30 de junio de 2014.

74. Ley de Instituciones y Procedimientos Electorales del Estado de Guerrero (LIPEEG). Periódico oficial, Chilpancingo, 30 de junio de 2014.

75. Ley de Instituciones y Procedimientos Electorales del Estado de Oaxaca (LIPEEO). Periódico oficial, Jalpan, Oaxaca, 21 de agosto de 2015.

76. Ley de Instituciones y Procedimientos Electorales del Estado de Sinaloa (LIPEES). Periódico oficial, Culiacán Rosales, 18 de diciembre de 2015.

77. Ley de Instituciones y Procedimientos Electorales para el Estado de Durango (LIPEED). Periódico oficial, Victoria de Durango, 03 de julio de 2014.

78. Ley de Instituciones y Procedimientos Electorales para el Estado de Sonora (LIPEES). Periodico oficial, Hermosillo, 30 de junio de 2014.

79. Ley de Instituciones y Procedimientos Electorales para el Estado de Tlaxcala (LIPEET). Periodico oficial, Tlaxcala de Xicohténcatl, 02 de septiembre de 2015.

80. Ley Electoral del Estado de Baja California Sur (LEEBCS). Boletín Oficial del Gobierno del Estado de Baja California Sur, La Paz, el 28 de Junio de 2014.

81. Ley Electoral del Estado de Chihuahua (LEECH). Diario Oficial de la Federación, Ciudad de México, 22 de agosto de 2015.

82. Ley Electoral del Estado de Nuevo León (LEEN). Periódico oficial, Monterrey, 08 de julio de 2014.

83. Ley Electoral del Estado de Querétaro (LEEQ). Periódico oficial, Querétaro, 15 de agosto de 2014.

84. Ley Electoral del Estado de Quintana Roo (LEEQ). Periódico oficial, Chetumal, 17 de noviembre de 2015.

85. Ley Electoral del Estado de San Luis Potosí (LEESLP). Periódico oficial, San Luis Potosí, 30 de junio de 2014.

86. Ley Electoral del Estado de Tamaulipas (LEET). Periódico oficial, Ciudad Victoria, 13 de junio de 2015. 
87. Ley Electoral del Estado de Zacatecas (LEEZ). Periódico oficial, Zacatecas, 07 de junio de 2015.

88. Ley General de Instituciones y Procedimientos Electorales (LEGIPE). Diario Oficial de la Federación, Ciudad de México, 23 de mayo de 2014.

89. Lineamientos que Regulan las Candidaturas Independientes para el Proceso Electoral 2014- 2015 (LRCIPE). Diario Oficial de la Federación, Ciudad de México, 7 de noviembre de 2014. 